\title{
High rate of abnormal glucose tolerance in Brazilian individuals undergoing coronary angiography
}

Valdecira M. Piveta', Fernando M. A. Giuffrida ${ }^{2,3}$, Celia S. Bittencourt', Carolina S. V. Oliveira' ${ }^{1}$ Pedro Saddi-Rosa ${ }^{1}$, Deyse M. Meira' ${ }^{1}$, André F. Reis ${ }^{1}$

\begin{abstract}
Introduction: Undiagnosed hyperglycemia is common in high cardiovascular risk individuals, especially in those with coronary artery disease (CAD). There is no consensus about the optimal method for the screening of hyperglycemia in this population. Subjects and methods: Five hundred and fourteen Brazilian individuals undergoing coronary angiography, without previously known diabetes mellitus (DM), had their glycemic status evaluated by both fasting plasma glucose (FPG) and HbA1c, being classified in normal (N), prediabetes (PD), and DM according to American Diabetes Association criteria. Concordance between both methods was assessed by Cohen's $\kappa$. Accuracy of FPG and $\mathrm{HbA} 1 \mathrm{c}$ to diagnose CAD was evaluated as proof-of-concept. Results: Among individuals screened by FPG, $41.2 \%$ had PD and $6 \%$ had DM. Among those screened by HbA1c, $52.7 \%$ had PD and $12.7 \%$ had DM. Concordance for a positive screening of PD occurred in 125 individuals ( $\kappa=0.084)$. Eighteen individuals had a concordant positive screening of $D M(\kappa=0.310)$. As a predictor of $C A D$, accuracy of FPG was $0.554(p=0.009)$ and of HbA1c $0.557(p=0.006)$. Conclusion: a high frequency of hyperglycemia, between 47 and $65 \%$, was found in individuals submitted to coronary angiography without previously known glucose disturbances, using FPG and $\mathrm{HbA} 1 \mathrm{c}$ as screening methods respectively. $\mathrm{HbA1c}$ detected significantly more individuals with both PD and DM than FPG. Concordance between both methods is low. The question of which is the gold-standard method to diagnose hyperglycemia in this population is still open. Arch Endocrinol Metab. 2015;59(4):367-70
\end{abstract}

Keywords

Cardiovascular disease; hyperglycemia; coronary angiography
${ }^{1}$ Centro de Diabetes, Disciplina de Endocrinologia, Universidade Federal de São Paulo (Unifesp), São Paulo, SP, Brazil

${ }^{2}$ Centro de Endocrinologia do Estado da Bahia (Cedeba), Salvador, BA, Brazil

${ }^{3}$ Universidade do Estado da Bahia (UNEB), Salvador, BA, Brazil

Correspondence to: Fernando M. A. Giuffrida Universidade do Estado da Bahia, Departamento de Ciências da Vida, Colegiado de Medicina Rua Silveira Martins, 2555, Cabula 41150-000 - Salvador, BA, Brazil fernando.giuffrida@me.com

Received on Mar/2/2015 Accepted on Mar/21/2015

DOI: 10.1590/2359-3997000000056

\section{INTRODUCTION}

$\mathrm{C}$ oronary artery disease (CAD) is frequently associated with glucose disturbances. Undiagnosed hyperglycemia is common in acute coronary syndromes (ACS) (1). Hemoglobin Alc (HbAlc) is a suitable option to screen for previous diabetes mellitus (DM) in this population since it bears some advantages such as showing less biological variability and not requiring fasting samples $(2,3)$. Although DM can remain asymptomatic for many years prior to diagnosis, acute hyperglycemia can ensue in clinical conditions such as ACS (4). This can lead to potential differences in the occurrence of glucose disturbances when individuals are studied electively or during these episodes, raising the question of a gold-standard method for diagnosing hyperglycemia. Some but not all studies have used the oral glucose tolerance test (OGTT) as such method, as comparator for either fasting plasma glucose $(\mathrm{FPG})$ or $\operatorname{HbAlc}(5,6)$.
In this study we aim to assess the frequency of DM and prediabetes (PD) in patients electively undergoing coronary angiography, using both FPG and HbAlc as classification criteria.

\section{SUBJECTS AND METHODS}

A total of 823 patients who electively underwent coronary angiography at the Federal University of São Paulo (Unifesp) were enrolled in the present study, according to previously described criteria (7). The study was approved by the ethics committee of Unifesp. After the exclusion of 309 individuals with previously known DM (38\% of our sample), 514 patients had their glycemic status assessed by FPG and HbAlc (HPLC). They were classified by both criteria according to American Diabetes Association guidelines in normal, PD, and DM (2). Individuals with impaired fasting glucose (IFG) were classified as PD for the sake of simplicity, since a unified nomenclature could be used for both diagnostic 
tools. CAD was defined as any stenosis $>50 \%$ in at least one major coronary vessel or branch. Cohen's kappa (к) was use to assess concordance between FPG and $\mathrm{HbAlc}$. The accuracy of both to predict CAD was assessed as area under ROC curve (ROC-AUC) and 95\% confidence intervals $(\mathrm{CI})$.

\section{RESULTS}

A high prevalence of $\mathrm{PD}$ was seen in this sample using both FPG (41\%) and HbAlc (53\%). DM was found in $6 \%$ and $13 \%$ using FPG and HbAlc, respectively (Figure 1). Diagnosis of PD was concordant in 125 individuals using both FPG and HbAlc. Agreement was very poor, with $\kappa=0.084$, despite being statistically significant. Only 18 individuals had concordant DM diagnoses by both methods, but agreement was moderate with $\kappa=0.310$ (Table 1). Accuracy of FPG in predicting CAD was $0.554(0.514-0.593), \mathrm{p}=0.009$. For HbAlc, ROC-AUC was 0.557 (0.517-0.597), $\mathrm{p}=$ 0.006 . Due to the poor accuracy values, no cut-point evaluation was attempted.

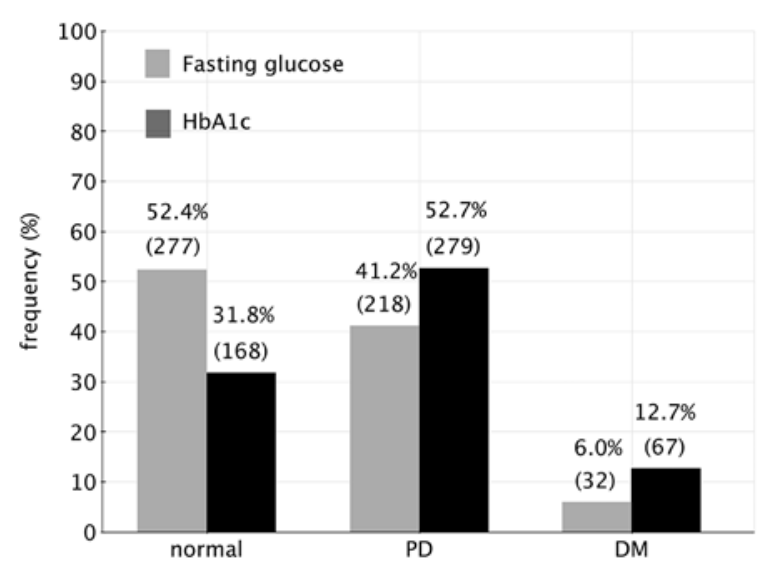

Figure 1. Relative frequencies of normal glucose tolerance, $\mathrm{PD}$, and $\mathrm{DM}$ according to the diagnostic method employed (values in parentheses are absolute numbers of individuals in each category).

Table 1. Concordance of PD and DM diagnosis made by both fasting plasma FPG and $\mathrm{HbA1C}$

\begin{tabular}{lccc}
\hline & $\begin{array}{c}\text { Number of individuals } \\
\text { with concordant } \\
\text { diagnosis }\end{array}$ & Cohen's $\kappa(\mathbf{9 5 \%}$ Cl) & p \\
\hline PD & 125 & $0.084(0.002-0.166)$ & 0.048 \\
DM & 18 & $0.310(0.185-0.435)$ & $<0.005$ \\
\hline
\end{tabular}

\section{DISCUSSION}

In this study a high frequency of glucose disturbances was seen in Brazilian individuals electively undergoing coronary angiography. We have compared FPG and $\mathrm{HbAlc}$ as methods to stratify glycemic status. HbAlc detected more individuals with both PD and DM than FPG. Accuracy of both methods to predict CAD, evaluated as a proof of concept, was very low.

In the Euro Heart Survey, the majority of 2,107 patients with ACS had altered glucose tolerance (AGT), more diagnosed with OGTT ( 60\%) than FPG $(\sim 20 \%)(8)$. Similar prevalence of AGT $(65 \%)$ was seen in a Chinese study of both elective patients and those with ACS. Approximately $85 \%$ of the cases would be undiagnosed without the OGTT. Interestingly, values were roughly compatible with the current classification (9), although there was no analysis of $\mathrm{HbAlc}$ as a diagnostic criteria in either case. In another study, among 401 individuals studied with CT angiography, $26 \%$ with newly diagnosed DM were found. Individuals with significant stenosis had higher FPG, post load glucose, and HbAlc than individuals without or with non-significant stenosis (10). Doerr and cols. analyzed the accuracy of $\mathrm{HbAlc}$ above $6.5 \%$ to diagnose DM in 1015 individuals undergoing coronary angiography, finding low sensitivity ( 18\%), but good specificity ( 97\%). In this study, according to HbAlc levels, 38\% had PD and $4 \%$ DM. A potential source of bias in this study was the adoption of the OGTT as the gold-standard for the diagnosis of DM. Besides, OGTTs were performed after the coronary angiography, therefore stress induced by the procedure could raise the frequency of false positive results in the OGTT, influencing the accuracy of $\mathrm{HbAlc}$ by disagreeing with it $(5)$. The influence of timing of OGTT has been hypothesized to compromise reproducibility of the results (4). In an Italian study of 780 individuals without previous DM, 53.9\% had $\mathrm{PD}$, with FPG, 2 -h post challenge glucose, and $\mathrm{HbAlc}$ diagnosing respectively $28.1 \%, 31.7 \%$, and $31.5 \%$ of individuals. There was poor agreement between FPG and HbAlc $(\kappa=0.332)$, and between 2 -h post challenge glucose and HbAlc $(\kappa=0.299)(11)$. Kowalska and cols. assessed 363 men without previous DM referred to coronary angiography (no ACS), finding 36\% with $\mathrm{PD}$ and $16 \%$ with DM, then concluding that most unrecognized glucose disturbances can be explained by FPG alone (12). In 400 Chinese adults admitted for coronary angiography, accuracy of HbAlc was similar to FPG in individuals without $\mathrm{CAD}$, but lower in $\mathrm{CAD}$ patients in the identification of DM $(\sim 21 \%)$ utilizing OGTT as the gold-standard (13). The differences observed among various studies could be attributable not 
only to the different diagnostic tests employed, but also to ethnic and demographic differences among studied populations.

This brings us to the debate whether HbAlc and FPG identify the same individuals is a relevant question. Any methods that evaluate blood glucose are in fact simplified ways to understand much more complex phenomena in the pathophysiology of DM, therefore a gold-standard for diagnosis DM and related disturbances may be regarded as virtually non-existent (6). Besides, limitations of $\mathrm{HbAlc}$ in the diagnosis of PD could further increase the complexity of this debate. While the ADA recommends the utilization of this method for the diagnosis of $\mathrm{PD}$, other recommendations such as those from the World Health Organization state that there is insufficient evidence to interpret $\mathrm{HbAlc}$ values below $6.5 \%$ with diagnostic purpose (14).

Another possible approach would be utilizing glucose measurements to estimate the risk of endpoints. We have assessed the accuracy of FPG and HbAlc to predict $\mathrm{CAD}$. Since there are already well-established diagnostic tools for $\mathrm{CAD}$, this was evaluated as a proofof-concept. Accuracy was low for both methods, leaving the question of which gold-standard test should be used as a comparator to be further investigated.

Some limitations of our study must be addressed. Firstly, glycemic status was not confirmed by a second laboratory measurements with either method. Therefore, patients cannot be regarded as having a diagnosis of PD or DM, but only a positive screening for those conditions. Secondly, PD is represented only by individuals with IFG. Impaired glucose tolerance (IGT) has not a strong agreement with IFG, since they represent different pathophysiological aspects of incipient glucose disturbance and may be associated with different cardiovascular risk profiles $(15,16)$. The absence of OGTTs in our investigation could lower the agreement ratio between blood glucose and HbAlc. Nevertheless, we think this group is adequate to represent a group of intermediate cardiovascular risk in between normal and DM.

In conclusion, $\mathrm{PD}$ and $\mathrm{DM}$ are highly prevalent in individuals without previously known glucose disturbances undergoing elective coronary angiography, being found in 47 to $65 \%$ of individuals, using FPG and $\mathrm{HbAlc}$ as screening methods respectively. Concordance between both methods is low, but the question of which is the best tool for identifying individuals at risk of both DM and CAD is still open.
Individual contributions: Valdecira M. Piveta researched data and wrote the manuscript; Fernando M. A. Giuffrida wrote the manuscript, performed statistical analyses, and supervised the project; Celia S. Bittencourt, Carolina S. V. Oliveira, Pedro Saddi-Rosa, and Deyse M. Meira researched data and wrote the manuscript; André F. Reis wrote the manuscript, researched data, supervised the project, and is the guarantor of the study. All authors have read and approved the final version.

Disclosure: no potential conflict of interest relevant to this article was reported.

\section{REFERENCES}

1. Ye $\mathrm{Y}, \mathrm{Xie} \mathrm{H}$, Zhao $\mathrm{X}$, Zhang $\mathrm{S}$. The oral glucose tolerance test for the diagnosis of diabetes mellitus in patients during acute coronary syndrome hospitalization: a meta-analysis of diagnostic test accuracy. Cardiovasc Diabetol. 2012;27;11:155.

2. American Diabetes Association: Standards of medical care in diabetes - 2013. Diabetes Care. 2013;36(Suppl 1):S11-66.

3. Vergès B, Avignon A, Bonnet $F$, Catargi B, Cattan S, Cosson E, et al.; Diabetes and Cardiovascular Disease study group of the Société Francophone du Diabète (SFD), in collaboration with the Société Française de Cardiologie (SFC). Consensus statement on the care of the hyperglycaemic/diabetic patient during and in the immediate follow-up of acute coronary syndrome. Diabetes Metab. 2012;38(2):113-27.

4. Kollias A, Diamanti-Kandarakis E. Oral glucose tolerance test in patients with undiagnosed diabetes and coronary artery disease: when should it be performed? Diabetologia. 2012;55(4):1221-2.

5. Doerr R, Hoffmann U, Otter W, Heinemann L, Hunger-Battefeld W, Kulzer $\mathrm{B}$, et al. Oral glucose tolerance test and $\mathrm{HbA}^{1} \mathrm{c}$ for diagnosis of diabetes in patients undergoing coronary angiography: [corrected] the Silent Diabetes Study. Diabetologia. 2011;54(11):292330.

6. Sattar N, Preiss D. HbA1c in type 2 diabetes diagnostic criteria: addressing the right questions to move the field forwards. Diabetologia. 2012;55(6):1564-7.

7. Bittencourt C, Piveta VM, Oliveira CS, Crispim F, Meira D, SaddiRosa $P$, et al. Association of classical risk factors and coronary artery disease in type 2 diabetic patients submitted to coronary angiography. Diabetol Metab Syndr. 2014;6(1):46.

8. Bartnik M, Rydén L, Ferrari R, Malmberg K, Pyörälä K, Simoons $M$, et al.; Euro Heart Survey Investigators. The prevalence of abnormal glucose regulation in patients with coronary artery disease across Europe. The Euro Heart Survey on diabetes and the heart. Eur Heart J. 2004;25(21):1880-90.

9. Hu DY, Pan CY, Yu JM; China Heart Survey Group. The relationship between coronary artery disease and abnormal glucose regulation in China: the China Heart Survey. Eur Heart J. 2006;27(21):2573-9.

10. Xu Y, Bi Y, Li M, Wang T, Sun K, Xu M, et al. Significant coronary stenosis in asymptomatic Chinese with different glycemic status. Diabetes Care. 2013;36(6):1687-94.

11. Marini MA, Succurro E, Castaldo E, Cufone S, Arturi F, Sciacqua A, et al. Cardiometabolic risk profiles and carotid atherosclerosis in individuals with prediabetes identified by fasting glucose, postchallenge glucose, and hemoglobin A1c criteria. Diabetes Care. 2012;35(5):1144-9. 
12. Kowalska I, Prokop J, Bachórzewska-Gajewska H, Telejko B, Kinalskal I, et al. Disturbances of glucose metabolism in men referred for coronary arteriography. Postload glycemia as predictor for coronary atherosclerosis. Diabetes Care. 2001;24(5):897-901.

13. Wang JS, Lee IT, LeeWJ, Lin SY, Fu CP,Ting CT, et al. Performance of $\mathrm{HbA} 1 \mathrm{c}$ and fasting plasma glucose in screening for diabetes in patients undergoing coronary angiography. Diabetes Care. 2013;36(5):1138-40.

14. World Health Organization. Use of glycated haemoglobin in the diagnosis of diabetes mellitus: abbreviated report of a WHO consultation. Geneva: World Health Organization; 2011.
15. Piveta VM, Bittencourt CS, Oliveira CS, Saddi-Rosa P, Meira DM, Giuffrida FM, et al. Individuals with prediabetes identified by $\mathrm{HbA} 1 \mathrm{c}$ undergoing coronary angiography have worse cardiometabolic profile than those identified by fasting glucose. Diabetol Metab Syndr. 2014;6:138.

16. Oliveira CS, Vieira JG, Ghiringhello MT, Hauache OM, Oliveira $\mathrm{CH}$, Khawali $\mathrm{C}$, et al. Diagnosis of hyperglycemia in a cohort of Brazilian subjects: fasting plasma glucose- and oral glucose tolerance test-based glycemic status are associated with different profiles of insulin sensitivity and insulin secretion. Diabetes Care. 2007;30(8):2135-7. 